sugar and alcohol, especially in countries where wood is abundant. There is, however, little prospect for making alcohol from waste sulphite-liquors in Great Britain, whilst production by fermenting cellulose is more likely to be developed in the overseas dominions than in our own country.

The outlook for producing motor-fuel from coal is considered to be favourable, but not by the lowtemperature carbonisation process, which, the Committee states, cannot yet be worked on a large scale at a profit, and when it can be so worked it would not provide more than a fraction of our requirements in heavy and light fuel-oil. The Bergius process (for the investigation of which the Government has recently granted the sum of $25,000 l$.) is stated to be the only one which could satisfy our requirements, but in view of the difficulty in constructing plant, some years must elapse before really commercial data concerning it can become available. In its remarks upon this process the Committee gives some quantitative data which are not up-to-date. The statement that at least one ton of coal must be burnt for every ton put through the process should read " one ton of coal is burnt as fuel for every two tons put through the process"; and the yield of light fuel is not I 5 gallons but from 20 to 25 gallons per ton, according to the quality of the coal treated. Further, the remark that " 65 per cent. of the weight of the coal may be converted into a kind of oil," would be more accurate in the form: "85"93 per cent. of the coal substance is converted into oil."

In its summary of this interesting section of the report, the Committee states that of all the processes not involving the distillation of fermented foodstuffs, the most likely to be adopted in Great Britain are those based upon the use of water-gas as raw material, and those by which fermentable sugars are obtained in high yield from wood. It is, however, strongly open to doubt whether the latter processes could be worked economically in Britain, where wood is scarce and expensive, and where wood-waste can only be collected and transported at prohibitive cost.

\title{
Discoveries in the Gobi Desert by the American Museum Expeditions. ${ }^{1}$
}

\author{
By Prof. Henry Fairfield Osborn, For. Mem. R.S.
}

T $N$ r 799, William Smith, then a young man of thirty; who was born at Churchill in Oxfordshire, dictated his now classic document, "The Order of the Strata," including a map showing the successive and characteristic fossils of southern Britain and the Oxford clay underlying this great University, with its Jurassic deinosaur Cetiosaurus. In the century and a quarter which has intervened before the present meeting of the British Association in Oxford, the twin sciences of geology and palæontology have reached a degree of precision which enables us, after our relatively brief and intensive surveys of the past four years, to declare 'the order of the strata' of Mongolia. Included in the Gobi Desert is a stratum equivalent in age to the Oxford clay of William Smith, containing the giant sauropod Asiatosaurus, a first cousin of the Oxford Cetiosaurus.

Meanwhile, physicists have extended the life-history period of the earth from the momentary 5000 years of Usher to the I,000,000,000 years of Rutherford. This allows a comfortable margin of 400,000,000 years' time for the wonderful procession of evolutionary advance recorded in the twenty-four chapters of Mongolian prehistory, beginning with the equivalent of the Purbeck and Oxford formations of Upper Jurassic time, continuing with the appearance of man in the Old Stone, Age, ending practically with the dominance of Ghenghis Khan, and followed by the decline of Mongolia to its present desert and relatively uninhabited state.

In the meantime, this now arid 'roof of the world" has been the scene of a whole succession of animal dynasties, fertile, productive, with a relatively temperate and invigorating climate, sometimes arid,

1 From an evening discourse delivered to the British Association at Oxford on August 9. For further information regarding these expeditions reference should be made to "Methods and Results of the American Museum Expeditions in the Gobi Desert, 1922-25" (NATURE, August 7 1926, pp. 198, 199), a lecture delivered to the Geological Society of London, x $926, \mathrm{pp}$. 198,
June $23, \mathrm{x} 926$.

$$
\text { NO. 2968, VOL. I I } 8 \text { ] }
$$

sometimes pluvial, from first to last the homeland of waves of migrating land reptiles and mammals, which successively spread into every other continent (Fig. I). It is a singular fact that this first and greatest of all life-centres (7) of prehistory was the last to be discovered, following by a half to three-quarters of a century the discoveries of great life-centres in Australia, in North and South America, in northern Africa, and in southern Asia. Although each of these great centres contributed its quota to the prehistory of the earth, none played a part at all comparable to that of central Asia.

With this introduction we may proceed to show by means of photography the contrast between the present geography of Mongolia and its palæogeography as recently revealed, and exhibit a new palæogeographic map of the world (Fig. I) prepared especially for this discourse, showing that by placing North America on the east, Asia in the centre, and Europe on the west of an equal-area projection, we have a complete solution of all the animal migratory routes from Upper Jurassic time to the six great waves of human migration which swept over northern Asia into North America in late Pleistocene time.

\section{Present Geography of Mongolia.}

The position of Mongolia in Asia as shown in the map of Perthes may be projected areally on a map of the United States along lines of the 4oth parallel; and there at once appears the remarkable similarity between the Mongolian fauna and that of the Rocky Mountain region throughout the entire period from Jurassic to recent times, the parallelism varying in closeness from epoch to epoch, at times Europe being closer than the United States. To the north of the hypothetical 'Gobia' lies 'Angara,' to the south the 'Gondwana' of Suess. 


\section{Personnel and Transportation.}

It has been estimated in the United States Geological Survey that as much was accomplished in three years by the American Museum survey as had been accomplished in the first fifty years of discovery in the corresponding Rocky Mountain region, namely, from 1850 until I900. This was due to prolonged palæontological experience in America and to the combination of slow camcl transport and rapid automobile transport, under the guidance of ten Mongols, ten Chinese, and an equal number of Americans trained in the western desert region. These rapid modern methods were rendered possible by the approval of the Mongol discovered the single rhinoceros tooth, hitherto the only fossil vertebrate found in all Mongolia. At Iren Dabasu Andrews pointed out to me distant fossil beds of the Wealden age on the horizon, a rich Lower Cretaceous level. Each of the watering stations mentioned in the above routes, where wells are sunk for the camels, now gives its name to a more or less great geological horizon or formation contemporaneous with the great horizons of western Europe or of the United States.

Nothing could exceed the fidelity and ability of the Mongols and of the Chinese; the former were found to be true to their word on every occasion, and the latter were not only faithful but also became extremely

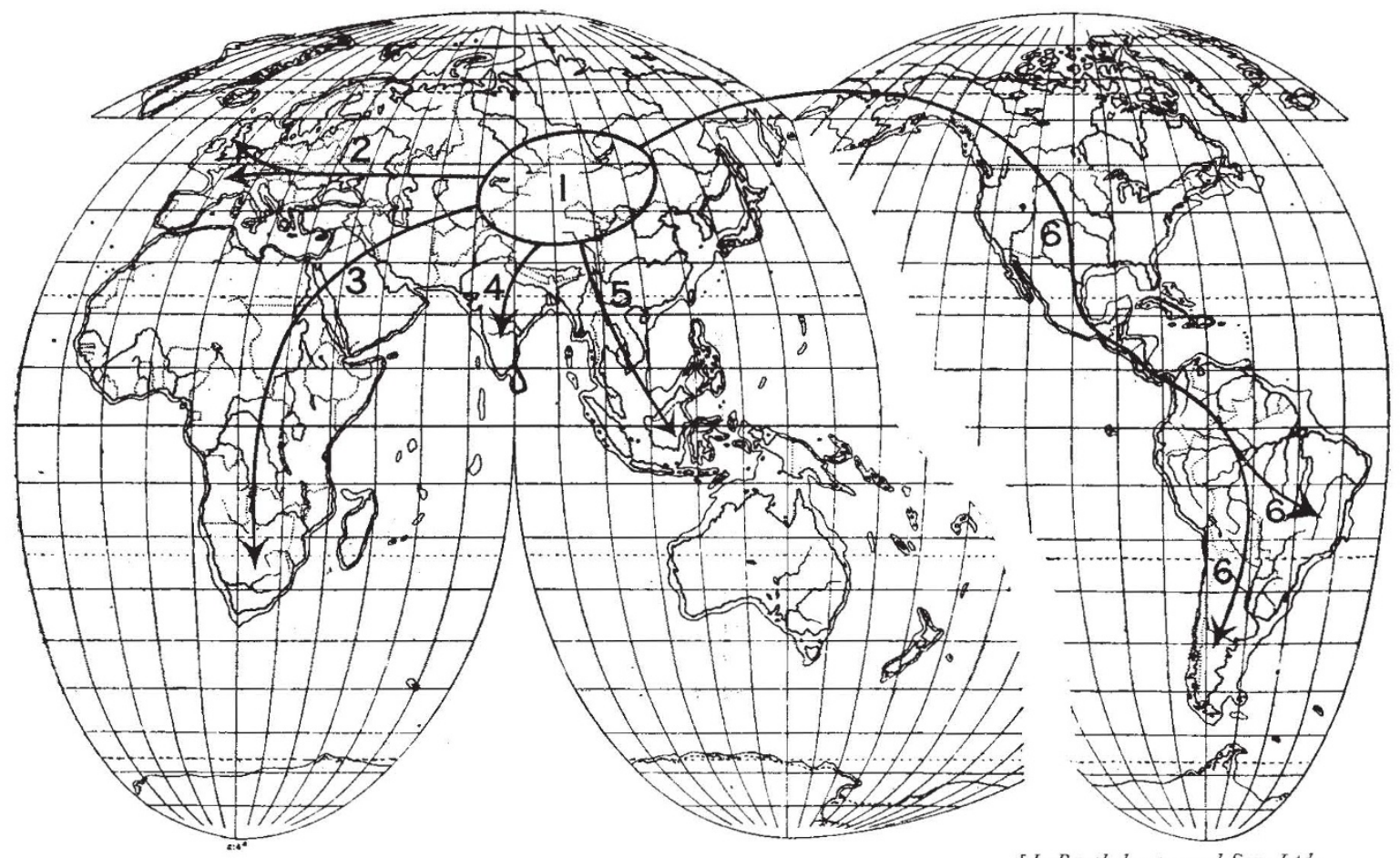

[J. Bariholomeze and Son, Ltd.

Fig. x.-1: New Central Asiatic continent. 2-6: Migration lines of the great reptilian Sauropota-to Europe (2), to South Africa (3), to India (4), to Malaysia (5), to North and South America (6).

Government, but neither aeroplanes nor radio were allowed admission. Over the great level stretches now traversed by wild asses and gazelles, the camels advanced fifteen miles a day, the automobiles a hundred and fifty miles a day, or ten times as rapidly.

The routes and discoveries of three seasons (19221925) may be summarised as follows :

(a) Peking, Kalgan, Pang Kiang, Irden Manha, Houldjin, Iren Dabasu, Tuerin, Urga (the main and only telegraph line in Mongolia).

(b) North-west Uliassutai route: Shara Murun, Ardyn Obo, Sair Usu.

(c) Altai route, travelling southward to Kolobolchi, Ondai Sair, Oshih (Ashile), Djadokhta, Gashato, Golobol'n Ola.

(d) Northward on the main route to Urga through Irden Manha, Houldjin, to Iren Dabasu.

Excepting Peking and Kalgan, all these localities yielded fossils, often in enormous quantities. At Houldjin we found the very spot where Obruchev expert in the discovery of fossils; and many of them are now engaged in working the fossils out of the rock in our Peking laboratory.

The Upper Jurassic Continent and Five LifezONES OF UPPER Mesozoic Time.

It is an interesting coincidence at the present meeting of the British Association that the oldest horizons, known as.Ondai Sair and Oshih (Ashile), are of sub-Wealden age and at present appear to be close to the Purbeckian and Oxfordian horizons of England. They contain primitive short-headed iguanodonts. Above them lies the Iren Dabasu, probably of Wealden age, containing large iguanodonts, ostrich deinosaurs, and megalosaurs. Still more recent are the famous Flaming Cliffs of the Djadokhta, which have no terrestrial equivalent in England; here were found the skulls of five small Cretaceous mammals and a host of deinosaurs, herbivorous and carnivorous, including the

NO. 2968, vOL. I I 8$]$ 
now famous Protoceratops with its supposed enemy, the Oviraptor or egg-snatching deinosaur. From the lower Ashile level the giant sauropods, Asiatosaurus, may have wandered to all the great continents except Australia. The fascination and the perils of fossil hunting among the Flaming Cliffs of Djadokhta for the eggs and skeletons of deinosaurs were recorded by instantaneous photography.

\section{Successive Life Phases of the Age of Mammals.}

Even closer and more continuous is the remarkable succession of Gobi formations starting with the basal Eocene Gashato, of the same age as the Thanet sands of England and rising through beds of the age of the London clay to the Hordwell and Headon of the Isle of Wight, where England's terrestrial formations are interrupted, presenting a series of extraordinarily close parallels with the great Rocky Mountain succession from basal Eocene to Miocene time. In the creodonts, uintatheres, and titanotheres of the Gobi region we discover close generic and almost specific affinities to their distant American cousins. But the giant Baluchitherium, which had ancestors in Upper Eocene time and attained its gigantic size in Upper Oligocene time, seems to have had a monopoly of the central and south Asiatic region, because it has never been found elsewhere. In the Miocene and Pliocene phases of the Gobi there are some breaks which will doubtless be filled by future discovery, but in the Middle Miocene, and again in the Upper Pliocene, we discover close kinship to Western Europe and North Africa, especially in the arrival of the proboscideans or mastodonts of remote African ancestry. Thus the high plateau region of central Asia, including. doubtless, Chinese Turkestan,
Tibet, and Mongolia, is firmly established as the previously missing area of origin not only of the terrestrial life of the entire northern hemisphere, but also of life which wandered into the extremities of Africa and of South America as well.

Scientific truth is far stranger than scientific fiction . Gobia takes the place of the mythical Atlantis and other imagined continents as the source of most of the animal civilisations and probably also of most of the vegetal civilisations of the northern hemisphere.

\section{Discovery of the Old Stone Age in 1925.}

At least four periods in the Old Stone Age of man were recognised in the campaign of 1925 , namely, in descending order, Azilian-Campignian, (?) Mousterian, Acheulean (much more doubtful), and (?) Eolithic. Directly opposite the Flaming Cliffs of Djadokhta was discovered a great human culture level believed to be of late Palæolithic, Campignian, and Azilian age, with thousands of implements, to the north-east of the Mousterian horizon discovered by Licent at Ordos in north China. Above this closing Old Stone Age level occurred, in order, traces of Neolithic, of Bronze, and of Iron ages, ending in traces of pre-Mongol peoples which are succeeded by burial-places of the Mongol race that ended with the warrior race of Ghenghis Khan and the conquest of all southern Asia by Kubla Khan.

Thus are written twenty-four new chapters in the prehistory of the earth by the expansion and elaboration of methods of research first introduced to the world of science by William Smith of Oxford in his chart showing the companionship of geology and palæontology, and in the most unexpected manner connecting Mongolia with England and, especially, with Oxfordshire.

\section{Observations with the Spectrohelioscope.}

\section{By Dr. Grorge E. Hale, For. Mem. R.S.}

$\mathrm{T}^{\mathrm{T}}$ HE spectrohelioscope described in my article on "Some New Possibilities in Solar Research" (NATure, July 3, 1926) has been provided with new oscillating slits and driving mechanism and an improved parallel-plate line shifter and micrometer for setting various parts of the $\mathrm{Ha}$ line on the second slit during observations, with divided arc indicating the exact wave-length employed. In this form the spectrohelioscope not only discloses the most delicate details of structure shown on the best Mount Wilson spectroheliograms, but has also served for the detection and measurement of some new and interesting phenomena.

Three cases observed on August I5 may be mentioned, all in the hydrogen vortices associated with the large spot group which on that day was near the central meridian of the sun. The first two were noticed south of the following spot of the pair. By rocking the parallel glass plate back and forth, thus showing the change in form with wave-length of two slender curved flocculi, their dark heads were seen to advance toward the spot as the $\mathrm{H} \alpha$ line was moved across the second slit from its centre toward the red. At a slit position about $\mathrm{r} \cdot 3$ angstroms from the centre of the line, the curved flocculi had disappeared, but their point-like extremities were still visible, projected against the outer boundary line of the penumbra. If we assume this effect to be caused by the rapid descent of the hydrogen in the vortex above the spot, the radial velocity was about $65 \mathrm{~km}$. per second. Another slender flocculus south of the preceding spot behaved in the same way. A similar observation on August I6 gave a maximum radial velocity of $56 \mathrm{~km}$. per second for the descending point. These velocities are of the same order as those of knots in prominences moving toward spots, measured by Slocum and Pettit on photographs of the sun's limb made with the Rumford spectroheliograph, and observed visually by myself with the spectrohelioscope.

Although I confirmed the new results on August 17 , the day I left Pasadena for a month's absence, I wish to check them more completely before expressing a final opinion as to their interpretation. It now seems probable, however, that the spectrohelioscope can be used for a more complete analysis than has previously been possible of the hydrogen vortices surrounding sunspots. These vortices involve the prominences as well as the chromosphere, and a means of measuring the velocities of the hydrogen, seen in projection against

$$
\text { NO. 2968, VOL. I I } 8 \text { ] }
$$

